\title{
Community Perception Regarding Maternity Service Provision in Public Health Institutions in 2018 and 2019: A Qualitative Study
}

This article was published in the following Dove Press journal: International Journal of Women's Health

\author{
Meklit Girma \\ Carmen Robles \\ Mekdes Asrat (D) \\ Hadgay Hagos \\ Measho G/slassie \\ Assefa Hagos
}

College of Health Sciences, Mekelle University, Mekelle City, Ethiopia
Correspondence: Meklit Girma Email meklitgirma36@gmail.com
Background: In the perspective of health care, community perception is defined as a combination of experiences, expectations and perceived needs. The community and client's perception of health services seem to have been largely ignored by health-care providers in developing countries. There is a knowledge gap about communities' perception and perspective of maternal health. If the community's perception is known, the quality of maternity care may be improved, maternal morbidity and mortality could be decreased, and the overall health of the mother can be improved. The aim of this study was to explore community's perception of maternity service provision in public health institutions.

Methods: A qualitative study with the underpinning philosophy of phenomenology was conducted in five subcities of Mekelle city, Ethiopia. Focus group discussions (FGDs) and in-depth interviews (IDSs) with participants who are residing in Mekelle city and who experienced maternity service as a client or as attendants were conducted to collect the necessary information. Using a semi-structured tool that has been translated into the local language, collected data were analyzed thematically using computer-assisted qualitative data analysis software ATLAS version 7. Qualitative data were transcribed through replaying the tape recorded interview from IDIs and FGDs. The text was carefully read and similar ideas were organized together. The participant's inductive meanings were extracted verbatim and described in narratives. The researcher and research assistants independently transcribed participant's comments verbatim to confirm the reliability of the findings.

Results: Participants reported that maternal health services in public health institutions were negative. Participants described experiencing poor staff attitude, lack of prescribed drugs in the institutional pharmacies, long waiting time, family proximity by professionals, poor attention to women during labor, lack of privacy and mistreatment made them develop a negative perception towards public health institutions. Despite these complaints, participants acknowledged public health facilities for affordable, accessible, qualified personnel and usually stocked with quality medications and equipment.

Conclusion: This study revealed that the community has a negative perception of the maternal health services in the public health institutions. The main reasons for their negative perception were poor staff attitude, unavailability of prescribed drugs in the institutional pharmacies, long waiting time, family proximity by professionals, poor attention to women during labor, lack of privacy and mistreatment.

Keywords: perception, maternity service, attitude, qualitative, maternal health

\section{Background}

From the perspective of health care, perception has been defined as a combination of experiences, expectations, and perceived needs. In addition, it has been defined 
as the client's subjective evaluation of their cognitive and emotional reactions due to the interaction between their expectations regarding ideal care and their perceptions of the actual care. Health-care quality is a global issue. People's perception is an important issue for both the evaluation and improvement of health-care services. ${ }^{1,2}$

Health-care providers in developing countries have largely ignored the community and client's perception of health services. Many studies have analyzed the community's and client's perception of health services and how the quality is influenced by their expectations, sociodemographic characteristics and clinical needs. ${ }^{3}$ Nowadays, the community's perception is a significant factor that has made health-care organizations successful. Therefore, the community's expectations and preferences must be considered. ${ }^{4}$ It is currently accepted that patients' opinions should supplement the usual indicators of quality in health care. ${ }^{5}$ However, this has only gained increasing attention over the past 20 years. $^{6}$

Maternal health is the health of a woman during pregnancy, childbirth and in the six weeks following delivery. ${ }^{7}$ The sustainable development goals (SGDs) are targeted to reduce maternal mortality to less than seventy per one hundred thousand by 2030 , and Ethiopia aims to reduce maternal mortality by two-thirds and improve maternal health. ${ }^{8}$ However, baseline data on the indicators of achieving the SDGs showed sluggish progress. ${ }^{9}$ A woman's lifetime risk of dying as a result of pregnancy and childbirth remains more than 100 times higher in subSaharan Africa than in high-income countries. ${ }^{10}$

Education on maternal care should include not only pregnant women but also men and key family members, such as mothers-in-law. ${ }^{11}$ A woman-friendly approach to the delivery of maternal health care based on women's concerns is necessary to improve women's access to maternal health and to reduce the number of health issues and deaths during childbirth, physical presence and emotional support from the companion. ${ }^{12,13}$ By accessing obstetrics care and having access to drugs and childbirth services, women are likely to be positively influenced to deliver at the hospital. ${ }^{14}$

Many studies analyzed how the patients' socio-demographic characteristics, expectations, and clinical needs affect their perception of health services. Moreover, in recent years, the characteristics of the external environment have also been considered as additional factors influencing individual evaluation. ${ }^{3,15}$
The World Health Organization promotes skilled attendance at every birth to reduce maternal mortality and morbidity and recommends that women's satisfaction be assessed to improve the quality and effectiveness of health care. Studies done in three developed countries showed that maternal care satisfaction is high, whereas in developing countries, it is not. ${ }^{16-18}$

A qualitative research conducted in Bangladesh shows that health facilities ignore community and patient perceptions because the facilities only focus on the services offered. ${ }^{5}$ One study in Nigeria shows that clients' perceptions are rarely examined in developing countries. There is a growing consensus that monitoring the quality of care should be based on patients' perception. ${ }^{19}$ Assessment of client perception of the quality of care and satisfaction with services has assumed a more prominent role in the last two decades. ${ }^{20}$ Another study conducted in Kenya shows that patients' perception of the quality of health services is influenced by their expectations, sociodemographic characteristics, clinical needs, and the characteristics of the external environmental factors affecting individual evaluation. ${ }^{3}$

Ethiopia is one of the countries that have the highest maternal mortality rates (MMR) in the world. Studies suggest that the quality of maternity care in Ethiopia is poor. The reasons are many; poor delivery experiences in health institutions, poor quality of skilled birth attendance, gender insensitivity, preservation of dignity, inadequate privacy, and unfriendly perception of care. ${ }^{21}$ University hospitals in Ethiopia are crowded with their students. In addition, many other students come from other private and governmental medical universities and colleges for education. ${ }^{4,22}$

Maternity care in Ethiopia has been making progress over the past two decades. Therefore, conducting this type of study has significant positive impact on maternal health. However, the country is not on track to achieve the target it has set. The intent of conducting this study is to explore the level of community's perception concerning maternity care and to summarize what we and do not know about several aspects of the community's perception of the quality of maternity care at public health institutions. Findings from this study may help policymakers and health professionals (health-care planners) to design or improve the quality of maternity care.

\section{Methods}

\section{Study Area}

The study was conducted in seven subcities of Mekelle city which is the capital city of Tigray National Regional 
State. It is located in the Northern part of Ethiopia, and is $783 \mathrm{~km}$ from the capital city, Addis Ababa. The coverage of ANC, facility delivery, and postnatal care were $100 \%$, $55.3 \%$, and $69.6 \%$, respectively. ${ }^{23}$ According to the 2013 census, the projected total population was 286,600 by $2019 .^{24}$ The study was carried out from August 2018 to February 2019.

\section{Study Methods}

A qualitative phenomenological study design was used. People residing in Mekelle city and who experienced maternity service as a client or as attendants were eligible. Study participants were selected with maximum variation for the in-depth interview (IDI) and the homogeneous purposive sampling method was used for the focused group discussion. The study was conducted in five subcities of Mekelle. Participants were selected by the researcher with the assistance of health extension workers.

\section{Participants}

Five focus groups discussions (FGDs) were carried out with a total of 50 participants. Two FGDs were held among mothers who have already given birth, Two FGDs were held among pregnant women and one FGD was held with attendants (husband, sister, and others) who were attending to their family members during maternity service at a public health institution;. Fifteen participants were selected for the IDI from members of the women's development army $(\mathrm{n}=7)$ and socially accepted persons $(n=8)$.

\section{Data Collection Procedure}

Data were collected through FGDs and IDI. Both FGDs and IDIs were conducted using a semi-structured interview tool translated into the local language, aided by voice recorder and key-note keeping. Fifteen IDIs were conducted and each participant was interviewed once. The interviews lasted between 45 and $55 \mathrm{~min}$. Five FGDs were carried out. Each FGD involved a minimum of eight participants to a maximum of 11 participants that lasted 80-100 min. Information about the purpose of the study and procedures during the discussion and interview were explained to obtain informed consent from each participant. FGDs were facilitated using a discussion guide that contained discussion points addressing issues related to what the participants liked during their visit, participants complaints about the service, the community's perception and finally the community's suggestion to improve the service. Data were collected by the researcher and trained graduates of BSc in Midwifery, who spoke the local language.

\section{Data Analysis}

Data were analyzed thematically using computer-assisted qualitative data analysis software (CAQDAS), Atlas.ti 7. Qualitative data were transcribed by replaying the tape recorded interview from IDIs and FGDs. Each FGD and IDI were thoroughly read and re-read to develop a coding scheme by the first author and reached an agreement on the coding approach. Coding was completed by going line by line through the material assisted by qualitative data management software, called open code. Codes were organized to create families and themes. The inductive meanings of participants were extracted and transcribed verbatim in narratives. Analysis was done using a thematic analysis approach.

\section{Results}

\section{Sociodemographic Characteristics}

A total of 65 participants were studied in five FGDs and 15 IDIs. The pregnant women, attendants (husband, sister, and others), socially accepted persons and women's development army in the study were almost all females in the reproductive age group and married. Most the participants learnt secondary and above and they were governmental workers some of them were enrolled in their own business and few of them were housewives and unemployed. The majority of them were orthodox in religion and some of them were Muslim and protestant (Table 1).

From the qualitative analysis of data, four major themes were derived. Participants were interviewed and discussed perception towards public health institutions of maternity service, facilities during their visit, participants' complaints about the service and the participants' suggestions to improve the service (Table 2). While the themes are reported as being discrete, there is considerable overlap among them. Further, participants' responses to interview questions often addressed more than one theme. In those cases, the interview data are described where they appear to fit most logically.

\section{Community's Perception Towards Public Health Institutions of Maternity Service}

Participants from the IDI and FGD had positive perceptions of the public health institutions: despite some 
Table I Participant's Sociodemographic Characteristics

\begin{tabular}{|l|l|l|}
\hline Characteristics & IDI & FGD \\
\hline Age & & \\
I5-45 & 13 & 45 \\
$\geq 46$ & 2 & 5 \\
\hline Sex & & \\
Female & 10 & 40 \\
Male & 5 & 10 \\
\hline Education & & \\
Informal educated & 1 & 5 \\
Primary and below & 4 & 25 \\
Secondary and above & 10 & 20 \\
\hline Occupation & & \\
Government & 5 & 21 \\
Housewife & 4 & 10 \\
Own business & 5 & 16 \\
Unemployed & 1 & 3 \\
\hline Marital status & & \\
Married & 12 & 41 \\
Single & 3 & 9 \\
\hline Religion & 3 & \\
Orthodox & Muslim & \\
Protestant & & \\
\hline
\end{tabular}

complaints, they described public health facilities as useful settings for maternity service. They were considered affordable, accessible, staffed by qualified personnel, and usually stocked with quality medications and equipment. They prefer public health institutions because they have well-equipped materials, the provisions of free maternity services, the availability of organized professional, and the provisions of guarantee for their life.

Participants from the IDI and FGD had a negative perception towards public health institutions: particularly the maternity service. They do not even want to go there especially to the hospitals because of the poor conditions or services they received. It is due to the provider's attitudes, facilities, students, and other conditions that they are not interested in public health institutions.

... I prefer the private clinics there is less patient flow and you have a great chance that you will meet the doctor in person and there are no students .... Last time when my child got sick, I took him to the nearest health center. He didn't feel better rather it worsened because they gave him a wrong drug ... (A husband from the focus group discussion participants.)
There are many rumors and real stories that participants know. Rumors harm the institutions. As they reported, they are afraid to go to public health institutions after they heard different rumors and real stories. They narrate their perception:

I remember one event. One day, a pregnant woman was in childbirth pain on the road. By the time she was alone and she has nobody around her..., so we took her to one of the hospitals. The nurse insulted her saying, why did you get pregnant if you can't handle the pregnancy by yourself. Why are you screaming now? I wasn't there when you opened your legs ... We asked the nurse why did she say these awful words to her and she was very disrespectful to us too. At that time we started to fight with the nurse ... (A woman from the focus group discussion participants.)

\section{Participant's Perception Regarding Facilities During Their Visit}

In-depth interviews and FGDs participants were satisfied with the care they received and they described public health institutions as useful settings for maternity services. In addition, participants preferred public health institutions thinking that, they are accessible, staffed with qualified personnel, usually stocked with quality medications and equipment, and the service is free. Furthermore, the satisfaction of these participants is soaring due to the availability of male health-care providers, the neatness of the institutions, and the care they received. They described their emotions in the following way:

I went to a public health institution to give birth. During childbirth their service was good they gave psychological support, they show me a good face, but during follow-up there was some problem on the due date. I haven't received bad treatment. (A woman from in-depth interview participant.)

Participants expected warm conversation, sharing, and empathy from their health-care provider. Because most community members have limited education, they strongly depend on oral advice and information from health-care workers. Preference for female providers emerged as a significant determinant of satisfaction with care in a developing country. ${ }^{24}$ However, this study found that participants prefer male providers because female providers misbehaved towards mothers especially in the delivery ward. The female provider's insult, moaning, mocking, and slapping show disrespect for mothers in labor. Female 
Table 2 Construction of Study Codes, Families and Study Themes

\begin{tabular}{|c|c|c|}
\hline Codes & Family & Themes \\
\hline $\begin{array}{l}\text { Caring, polite, respectful, soft-hearted, patient and are good in every } \\
\text { respect } \\
\text { Affordable, accessible, staffed by qualified personnel }\end{array}$ & $\begin{array}{l}\text { Male midwife } \\
\text { Like about the service }\end{array}$ & $\begin{array}{l}\text { Community's perception } \\
\text { Facilities during participants } \\
\text { visit }\end{array}$ \\
\hline $\begin{array}{l}\text { Poor attention to women during labor } \\
\text { Humiliation, abuse at the mother even slap } \\
\text { Yelling and insulting } \\
\text { Embarrassing/shameful } \\
\text { Family proximity } \\
\text { Female health professionals } \\
\text { Prohibited to have companionship after they examine them they did not } \\
\text { tell them about their conditions of heath } \\
\text { Lack of prescribed drugs } \\
\text { Lack of bed and bed sheets } \\
\text { Lack of scanning ultrasound, } \\
\text { Unable to reaches to ambulance, } \\
\text { Dirty public health institution } \\
\text { Incompetence } \\
\text { Mistreatment, misdiagnosis } \\
\text { Episiotomy is routinely done without indication } \\
\text { Repeated examination } \\
\text { Not punctual, long waiting time } \\
\text { Overcrowding } \\
\text { Lack privacy during examination and delivery time }\end{array}$ & $\begin{array}{l}\text { Emasculate woman's feeling and } \\
\text { experiences } \\
\text { Being discriminated } \\
\text { Poor staff attitude } \\
\text { Infrastructure } \\
\text { Mismanagement } \\
\text { Delays from the health workers to } \\
\text { respond to their needs } \\
\text { Students }\end{array}$ & $\begin{array}{l}\text { Participants' complaints about } \\
\text { the service }\end{array}$ \\
\hline $\begin{array}{l}\text { Any regulation for the number of students } \\
\text { - Workers to become good and passionate } \\
\text { - Administrative part should take measures }\end{array}$ & Comments & $\begin{array}{l}\text { Community's suggestion to } \\
\text { improve the service }\end{array}$ \\
\hline
\end{tabular}

health-care providers in general exhibit poor attitude towards pregnant and laboring mothers. ${ }^{23}$ Participants prefer to be seen and examined by male midwives because they are caring, polite, respectful, soft-hearted, patient, and good in every respect. The experience stated by two participants can be read as:

Providers who work in public health institutions have some problems. Actually, I prefer male health-care providers. They treat you well, they are tolerant and softhearted but females are moaners and are not caring I don't know why they are not good, even they may insult and slap you ... (A woman from focus group discussion participant.)

However, other participants have different ideas with regard to the idea stated above. They do not like to be seen by male providers. This is because sometimes males are cruel in their action. As a result, women may be shy and hate to be treated by males. One of the participants shared her experience as:
I have a complain on the doctors especially, when I give birth, they nag and moan at me. They insult mothers, it is better if they didn't insult. Especially the male doctors insulted me because I didn't drink milk when I gave birth. Mothers go to the health institutions to get better and better treatment .... (A woman from focus group discussion participant.)

\section{Participants' Complaints About the Service}

Community complaints about public health institutions both from IDIs and FGDs as well as the community's complaints from both sides are listed in Figure 1. Lack of ambulance, mistreatment from the care giver, no attendant allowed to accompany during labor and delivery and no emotional support during labor and delivery were some of the complaints pointed out from the IDIs. Beside these complaints, episiotomy was done to every mother in hospitals, lack of privacy during labor and delivery and misdiagnosis were other complaints mentioned by FGD 


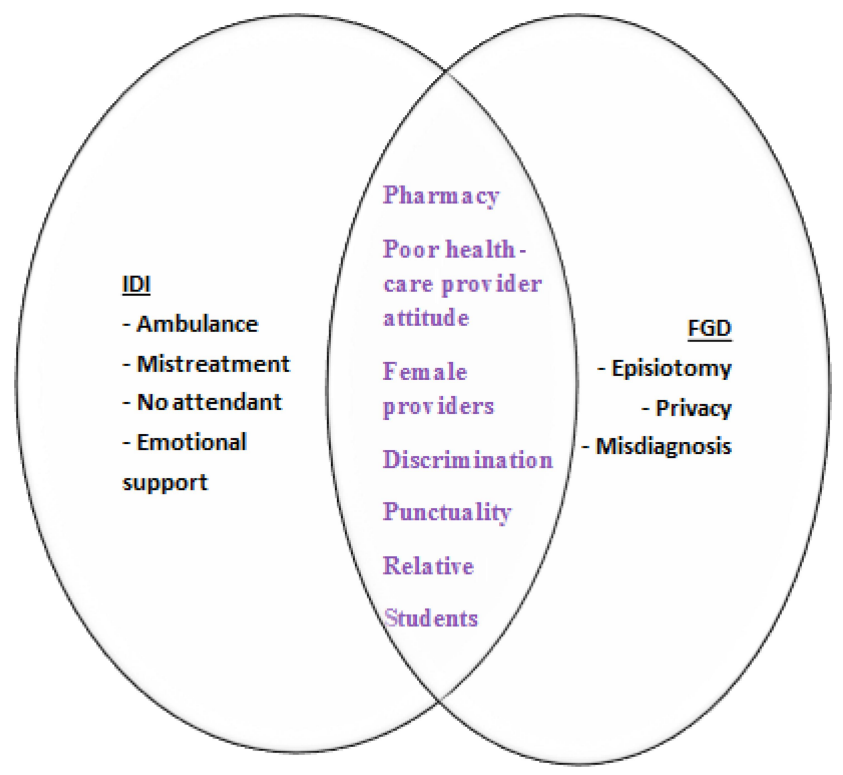

Figure I Community's complaints on public health institutions.

participants. In addition to these, complaints about pharmacies and pharmacists in the public health institutions, poor health-care providers especially female providers, discrimination from the care providers, health workers punctuality, family proximity providers giving priority to their relatives, lack of privacy due to large number students and some other complaints were revealed both by FGD and IDI participants.

The study found that despite the participants who reported being happy with the maternity care services acquired however, they have experienced some challenges associated with service delivery at some public health institution in the city like shortage of beds, bed sheets and blankets not only the shortages, sometimes there are dirty beds - especially at night, problems with punctuality. Participants complained that there were a lot of delays from the health workers in responding to their needs, this study found that mother's lack privacy during examination and delivery time due to overcrowded by students. Reasons for unhappiness included poor staff attitudes, long waiting times, poor attention to women in labor, drug availability, lack of privacy due to large number students, mistreatment, misdiagnosis, and other services (Figure 1).

The negative views expressed about public maternity services are lack of sympathy, poor commitment and attitude, lack of life-saving equipment and supplies in the context of care. Participants reported that they are unsatisfied with the maternity service they received during their pregnancy, delivery, and after delivery. Poor staff attitudes, long waiting times, poor attention to women during labor, lack of beds, scarcity of drugs, lack of privacy due to large number of students, mistreatment, misdiagnosis, and others are mentioned as the specific areas of service dissatisfaction.

.... At one of the hospitals, there was a big problem my son developed a heart problem because he lost blood from this cord because they left untied during birth..... Finally, they told me that he had a heart problem.

At the time of childbirth my birth canal was open, but they told me that I am not reaching to that level and laugh when I told them the baby was coming out ... I was bleeding too, and left alone. Finally the head was out and my birth canal was torn out after that they run to help me that's why they didn't tie cord because they were shocked. This all happens because they were careless ...... (Expressed her emotion with a loud voice.) (A woman from focus group discussion participant.)

The study found that those participants who reported being happy with the maternity service services had also some challenges associated with service delivery in some public health institutions in the town. These challenges include drug availability, ultrasound, ambulance service, cleanliness of the public health institutions and availability of a bed. In some public health institutions, there is no operational ultrasound machine for scanning. During the FGDs and IDIs, all the participants stated that ultrasound and drug supply are the prominent problems in all health centers.

.... In one hospital, my wife was told on the day of childbirth that our baby had a big swelling on his back. They told us she needed an operation. She had been attending at the health Centre and scan one time during her follow-up and they never told her about it ... (A husband from the focus group discussion participants.

The availability of prescribed drugs in the public health institutions is a significant predictor of mothers utilizing the maternity services of a public health facility. However, participants complained about pharmacies and pharmacists in the public health institutions because even though drugs are available, mothers may not get the drug they need due to pharmacists' attitude. They work by family proximity, they prioritize serving relatives and close friends. As a result, participants believe that pharmacists have serious problems. Their complaints described in their own words as: 
There is a big problem related to pharmacy, whenever doctors prescribe a drug all are unavailable in the hospital and always link to private health institutions .... Supplies and service for maternity service are free that is the government's promise, but you don't get full service in public health institutions. Even the drug is available, they said no and moaning at you they said "sitting down, go there, come here". Even you politely ask, they will shout at you. They got a serious problem; they disrespect you and sell the drug for people they know. (A husband from the in-depth interview participants.)

Participants complain, not only about the shortage of beds, bed sheets, and blankets, but also about the neatness of the beds, especially at night time, in hospitals. Mothers are forced to spend the whole night outside and exposed to chilly weather. Moreover, providers leave mothers in the hospitals. They explained their complaints in the following way:

I go there at night-time I was in childbirth pain, but they couldn't give me bed because there was no open bed..... So I spent the night outside. (A woman from the focus group discussion participants.)

The study found that there is a problem related to the health workers punctuality. Participants complained about the delays from the health workers to respond to their needs, They spend much of their time in the cafeteria. In addition, there is a perception about clinics that patients should wait a long time until they get services. Long queues are also experienced on antenatal and postnatal visits. Long tea-breaks resulted in delayed attention to mothers. They stated:

The service is not good. They appoint you again and again. Actually it is not far for me, but it is not fair for those mothers who come from a remote area ... The reason for repeated appointments is because the professionals are not punctual .... For one checkup you will be there for more than 4 days. .... For a mother who came from far. There is no responsible person who is responsible about the time of entry and exit because health care workers enter at 9AM (3LT) and exits at 11AM (5 LT). They are not punctual .... they are careless and respect us less. (A woman from the focus group discussion participants.)

This study found that mothers lack privacy during examination and delivery especially at hospitals. There is no privacy at all since a high number of students are present during the provision of service for a single mother. Furthermore, participants had a good attitude regarding students, but suggest limiting their number to two or three, and only one student should be allowed to examine one mother. In general they do not have a problem with students because students are the future professionals as they stated.

I had many students in attendance when I gave birth. But I was good for them because they are fresh they want to learn even they make operation of my birth canal for learning purpose. If they were fewer I might be ok. It's a shame to be seen by many students. Since they should be learning they should be 2-3 is a better number. And being supervised by their teacher is good because they are future doctors ... (A woman from focus group discussion participants.)

However, there are no rules and regulations that prescribe the number of students allowed to enter the delivery room when a single mother comes for delivery. Because of this, the rooms become overcrowded, mothers feel frustration and discomfort. As a result, participants developed negative attitudes and perceptions towards students. Participants explained their feelings as:

I don't want a lot of people to surround me while I give birth, of course I know they were students but I don't want people to make me uncomfortable ... There were a lot of students in the room. The nurse asks me to sit with legs up position and I refuse because I was very stressed by the crowd of the students. Suddenly the nurse starts shouting at me. Even if I'm not comfortable I gave birth with those students in the room. I don't believe that is recommended. (She expresses her emotion by increasing her voice.) (A woman from the in-depth interview participants.)

There is a consensus among participants in the preferences of private institutions over public health institutions due to the cooperation of the health-care providers, the sympathy they show, the treatments they provide, and the respect that they have.

I prefer the private health institutions one there is less patient flow and you have a great chance that you will meet the doctor in person and also there are no students in the private health institutions. They are very conscious about their job because they want to keep their name. You will get good service. Last time I took my friend to a public hospital. She has been treated by nurses. They didn't even give her a bed. But when I get a private health institution, she gets a clean bed and good treatment. That is why I preferred private clinics ... (A woman from the focus group discussion participants.) 


\section{Community Suggestions to Improve the} Service

Finally, participants were asked their perspectives for the improvements of the maternity service in public health institutions in general. Consequently, they suggested that drugs should be made available whenever mothers are in need. Workers in the public health institutions should be passionate about their work and they should be exemplary for interns. To keep the privacy of mothers, the number of students should be limited to two or three. Health-care providers should be punctual. Participants also commented on facilities like the shortage of bed sheets, the neatness of the hospitals, and shortage of ambulances. Further comments were also provided; health-care providers give poor treatment to mothers. Therefore, the administration and the concerned bodies should take corrective measures because a little mistake may cost a life.

\section{Discussion}

This study explored the perception of the community toward public health institutions regarding the maternity service delivery system in the subcities of Mekelle city and their complaints about the service. The study also explores recent information on different challenges in terms of access and quality of maternal health-care delivery in public health institutions on prenatal, intranatal, and postnatal care services.

Participants had a negative perception of public health institutions specifically on maternity service delivery. Participants reported that the services rendered by public health institutions were poor. The indicators are many: poor staff attitudes, lack of prescribed drugs in the institutional pharmacies, long waiting times, family proximity by professionals, poor attention to women during labor, lack of privacy, and ill-treatment. As a result, participants developed negative attitudes towards public health institutions, and they prefer private health institutions. This study shows similar results with the results identified in Nigeria. The study in Nigeria showed that health seekers experience vast personal and structural challenges in reaching and accessing quality care. ${ }^{25}$ Most public health facilities in Nigeria, lack basic equipment and are sometimes staffed by hostile and unfriendly providers. These are the reasons why women often preferred traditional rather than modern facilitybased maternity service. Participants reported their key constraints in the context of care-seeking to include unsafe and poorly resourced care services and unprofessional and abusive providers. Abuse of mothers during childbirth is a health facility failure and a violation of women's rights as well as an important barrier to women seeking institutional delivery. ${ }^{13,26,27}$

As a result, participants prefer and encourage others to visit private health institutions. In private health institutions, as participants reported, health-care providers are passionate with a welcoming face and approach clients in a respectful manner. This implies that the choice of places during labor and delivery has a significant positive impact on women satisfaction with the overall birth experiences. This finding is supported by studies carried out in Brazil and Malawi. ${ }^{7,13}$ Friendly care was important for the mother's gratification. Respect and politeness, communication skills and technical competence were strong predictors of patient satisfaction. ${ }^{15}$

Mothers' experiences of threats, unfriendly health-care providers in health-care facilities were factors that discouraged women from seeking care at public health institutions. Interviews with participants showed that respect and a nonjudgmental mother-caregiver relationship allow communication, friendly and nonabusive attitude to flow between caregivers and women, and did have an effect on uptake of services. The findings in this study are supported by literature from Ghana, Malawi, and Ethiopia that showed that bad relational practices of health-care providers have a negative effect on access to, and equitable use of experienced care. ${ }^{18,23,28-30}$

Furthermore, this study found that one of the major determinants of maternal satisfaction emerges from the availability of drugs and equipment. Participants in this study reported problems with the pharmacy in the public health institutions. This finding is similar to the studies conducted in Benin Teaching Hospital, Nigeria, Malawi, Jima Tigray Zonal hospitals in that the availability of supply had significant impact on maternal satisfaction. However, lack of drugs and supplies in the hospital pharmacies were the major problems, and participants were unhappy with the pharmacy department. ${ }^{18,31,32}$ This study showed that there was a punctuality problem among the health providers. Participants reported that professionals are not punctual in public health institutions. As the study shows, since professionals spent much of their time in the compound cafeteria and lounge, mothers are appointed frequently to come back another time. This finding is similar to some studies conducted in Argentina, South Africa, Malawi, Nigeria, and India. $15,28,33,34$

The other remarkable result emerging from the data is that participants at public health institutions allowed 


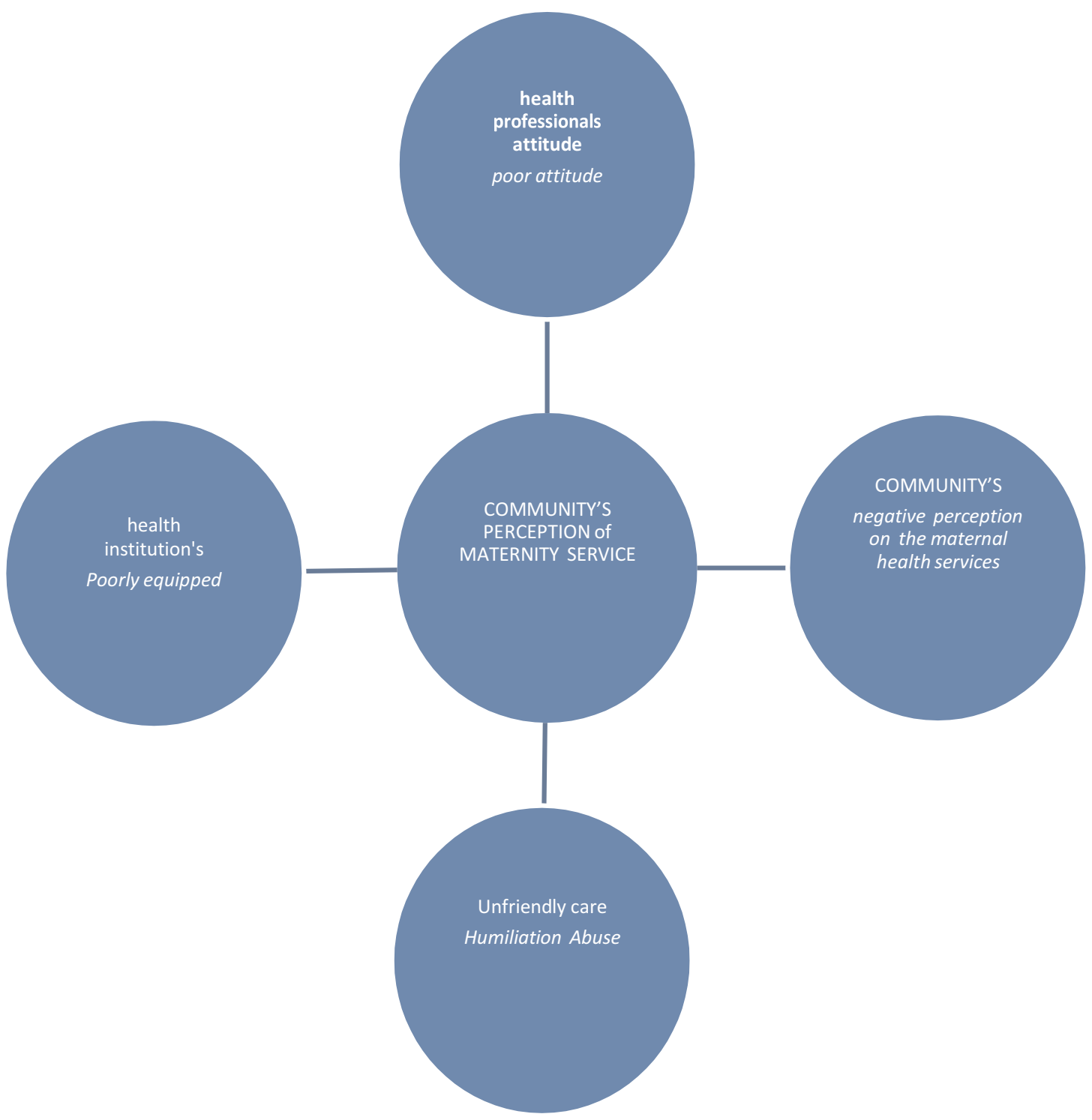

Information Classification: General

Figure 2 Theoretical framework.

medical and premedical students to supervise them during their examination. These results are comparable with studies conducted in Ghana and at King Abdul-Aziz University Hospital where participants would allow medical students to read their medical file, were present during ward rounds, and present in the outpatient department during their consultations. The similarity might be due to the minimal direct contact between the mother and the student, and minimal involvement of students in providing medical care. ${ }^{30,35}$ However, participants disagreed about being seen by students. The participants reported that they had complained about the number of students, privacy and their skill. Participants disagreed about the number of students as they sometimes reported their number became greater than ten just for one mother and the mother had no privacy. Different studies (Saudi Arabia, Malawi, and Tikur Anbesa) support the result of this study; inadequate privacy during antenatal checkup and counseling were associated with women's negative perception of services. Lack of confidentiality during checkups and deliveries discourage mothers from going to public health institutions. A potential reason for this increase in denials is that 
patients might have a low confidence in medical students' skills in gathering a complete medical history that could help in reaching the diagnosis. ${ }^{15,28,36,37}$ There was relatively low acceptance of students in the maternity, gynecological, labor and delivery wards, which were similar with results of a study done in Kuwait. ${ }^{38}$

\section{Conclusion}

Evidence from participants' (FGD, or interviews), show that the community's perception on maternal health services was negative, their commonly mentioned reasons for their negative perception were poor staff attitude, lack of prescribed drugs in the institution pharmacies, long waiting time, family proximity by professionals, poor attention to women in labor, overcrowding, lack of privacy, and mistreatment. Despite these complaints, participants acknowledged public health facilities for affordable, accessible, qualified personnel and usually being stocked with quality medications and equipment. Listening to the voice of the people in studies such as this one affirms the importance of the community in health-care planning. It is recommended that the attributes falling under fulfilment from the treatment process like waiting time, privacy, continuity of care, medicines and investigations should be addressed, Medical educators should closely monitor their students' and it is necessary that universities and colleges training students consider other support options for clinical practice. The strengths of the current study are the inclusion of husbands, mothers, and other relatives, and information is gathered extensively from these sources Figure 2.

\section{Abbreviations}

ANC, antenatal care; SGDs, sustainable development goals.

\section{Data Sharing Statement}

All the supportive material will be available when it is necessary.

\section{Ethical Consideration}

The study was conducted according to the Declaration of Helsinki. Information about the purpose of the study and procedures during the discussion and interview were explained to obtain informed consent from each participant. Before the actual data collection an ethical clearance letter was obtained from Mekelle University, College of Health Sciences, and Health Research Ethics Review Board (HERB), (reference no: ERC 1516/2018) and a support letter was obtained from the Tigray Regional Health Bureau. Informed oral consent or permission was obtained from the study participants. The objective of the study was explained to the study participants, privacy, and confidentiality was ensured. Furthermore, the study participant's involvement in the study was voluntary.

\section{Acknowledgments}

The authors are grateful to Mekelle University and its project (MU-HU-NMBU) for financial and technical support. We also thank all participants who took part in the study. We are grateful to the Tigray Regional Health Bureau.

\section{Author Contributions}

All authors made substantial contributions to conception and design, acquisition of data, or analysis and interpretation of data; took part in drafting the article or revising it critically for important intellectual content; agreed to submit to the current journal; gave final approval of the version to be published; and agree to be accountable for all aspects of the work.

\section{Funding}

Mekelle University, MU-HU-NMBU project supported this study financially. These funding agents had no role in designing the study, data collection, analysis, and data interpretation, and writing the manuscript.

\section{Disclosure}

The authors report no conflicts of interests in this work.

\section{References}

1. Jiwa M, Mcmanus A, Dadich A, Hewitt V. The impact of knowledge, attitudes and beliefs on the engagement of primary and community-based healthcare professionals in cancer care: a rapid review; 2012.

2. Virk A, Kalia M, Gupta BP, Singh J. A study to evaluate patient expectation and satisfaction in a tertiary care teaching hospital. Healthline. 2013;1(1):4.

3. Yegon CWK. Obit regression models by patient factors influencing satisfaction with quality of healthcare in kenya: a comparison of ordered logit and ordered PR. 2013.

4. Chand BB, Katuwal SB, Pandit R. Satisfaction with quality of health care among teaching hospitals in kathmandu, satisfaction with quality of health care among teaching hospitals in Kathmandu, Nepal. Asian $J$ Med Health. 2018.

5. Science S. Service quality perceptions and patient satisfaction: A study of hospitals in a developing country. Soc Sci Med. 2016;52 (9):1359-1370.

6. Boyer L, Francois P, Doutre E, Weil G, Labarere J. Perception and use of the results of patient satisfaction surveys by care providers in a French teaching hospital. Int J Qual Health Care. 2018;18:359-364. 
7. Ogu RN, Alegbeleye JO. Improving maternal health: women , $\mathrm{s}$ attitude to antenatal care utilization is crucial. Clin Obstet Gynecol Reprod Med. 2018;4:1-3.

8. Commitments G, Ownership N. Federal Democratic Republic of Ethiopia The 2017 Voluntary National Reviews on SDGs of Ethiopia: government Commitments, National Ownership and PerformanceTrends Content; 2017.

9. Transforming our world: the 2030 agenda for sustainable development. Available from: https://www.preventionweb.net/go/ 45418. Accessed September 4, 2020.

10. Koblinsky M, Moyer CA, Calvert C, et al. Maternal Health 6 Quality maternity care for every woman, everywhere: a call to action. Lancet. 2016;6736.

11. Pembe AB, Urassa DP, Darj E, Carlstedt A, Olsson P. Qualitative study on maternal referrals in rural Tanzania: decision making and acceptance of referral advice. Afr J Reprod Health. 2008;12(2):120-131.

12. Srivastava A, Avan BI, Rajbangshi P, Bhattacharyya S. Determinants of women' $s$ satisfaction with maternal health care: a review of literature from developing countries. BMC Pregnancy Childbirth. 2015;15:1-12.

13. Taheri M, Takian A, Taghizadeh Z, Jafari N, Sarafraz N. Creating a positive perception of childbirth experience: systematic review and meta- analysis of prenatal and intrapartum interventions. Reprod Health. 2018;15:1-13.

14. Holmes W, Goldstein M. Being treated like a human being: attitudes and behaviours of reproductive and maternal health care providers Mother and baby in the marketplace in Lagos; 2012:1-87.

15. Ahmad I, Nawaz A, Khan S, Khan H, Rashid MA. Prediction of patients' attitude towards healthcare services. 2015

16. Gebrehiwot Y. Assessment of client satisfaction in labor and delivery services at a maternity; 2014.

17. Aston M, Robb K, Practitioner M. Care experiences of provider client relationships christine saulnier, midwifery coalition of nova scotia. 2006

18. Machira K, Palamuleni M. Women' s perspectives on quality of maternal health care services in Malawi. Int $J$ Women's Health. 2018;10:25-34.

19. Musa O. Perception of patients on quality of health care services at a teaching hospital in; 2005.

20. Ong LM, De Haes JC, Hoos AM, Lammes FB. Doctor- patient communication: a review of the literature. Soc Sci Med. 1995;40, 903-918.

21. Weir Z, Bush J, Robson SC, Mcparlin C, Rankin J, Bell R; 2010. Available from: https://www.sciencedirect.com/science/article/pii/ S1871519216302517. Accessed September 4, 2020.

22. Mishra PH, Mishra T. Study of patient satisfaction at a super specialty tertiary care hospital. Indian J Clin Pract. 2014;25(7):624-634.

23. Gebremichael MW, Worku A, Medhanyie AA, Edin K. Women suffer more from disrespectful and abusive care than from the labour pain itself. BMC Pregnancy Childbirth. 2018;18:392.
24. Mashego T. Community perception of quality of (primary) health care services in a rural area of Limpopo Province, South Africa: a qualitative study; 2002.

25. Ezeonwu M. A collaborative communitywide health fair: the process and impacts on the community. $J$ Community Health Nurs. 2014;31:118-129.

26. Hamer DH. Epidemiology of congenital malaria in Nigeria: A multi-centre study Epidemiology of congenital malaria in Nigeria: a multi-centre study. Trop Med Int Health. 2007;12(11):1279-1287.

27. Okonofua F, Ogu R, Agholor K, Okike O, Abdus-salam R, Gana M. Qualitative assessment of women's satisfaction with maternal health care in referral hospitals in Nigeria. Reprod Health. 2017;14:1-8.

28. Guidelines, U. Determinants of women's satisfaction with maternal health care: a review of literature from developing countries. $B M C$ Pregnancy Childbirth. 2015;15:97.

29. Ma B, Gj H, Sakala C, Rk F, Cuthbert A. Continuous support for women during childbirth (Review). Cochrane Database Syst Rev. 2017.

30. Ganle JK, Parker M, Fitzpatrick R, Otupiri E. A qualitative study of health system barriers to accessibility and utilization of maternal and newborn healthcare services in Ghana after user-fee abolition. BMC Pregnancy Childbirth. 2014;14:1-17.

31. Ofili AN, Ofovwe CE. Patients' assessment of efficiency of services at A. 2005;4:150-153.

32. Assefa F, Mosse A, Michael YH. Assessment of clients 'satisfaction with health service deliveries at Jimma University specialized hospital. Ethiop J Health Sci. 2011;21(2):101-110.

33. Izugbara CO, Wekesah F. What does quality maternity care mean in a context of medical pluralism? Perspectives of women in Nigeria. Health Policy Plan. 2018;33:1-8.

34. Obukowho OL, Olukemi AE, Uche A, Chijioke A, Ngo BN, Ikechukwu O. Inpatients' perception o f doctors' a ttitude towards the management of their ill health in a Nigerian University Teaching Hospital. 2017;16:102-109.

35. Sayed-hassan RM, Bashour HN, Koudsi AY. Patient attitudes towards medical students at Damascus University teaching hospitals. BMC Med Educ. 2012;12:13.

36. Al-khatib T, Othman SB, El-deek B. Patients' perception toward medical students ' involvement in their surgical care: single center study. Educ Res Int. 2016.

37. Temesgen WA. Original article patients ' attitude towards medical students involvement in their health care at Tikur Anbessa specialized hospital, Addis Ababa 2010. Ethiop J Health Sci. 2013;23(2):158-64.

38. Marwan Y, Al-saddique M, Hassan A, Karim J. Are medical students accepted by patients in teaching Hospitals? Med Educ Online. 2012;17:17172.

\section{Publish your work in this journal}

The International Journal of Women's Health is an international, peerreviewed open-access journal publishing original research, reports, editorials, reviews and commentaries on all aspects of women's healthcare including gynecology, obstetrics, and breast cancer. The manuscript management system is completely online and includes a very quick and fair peer-review system, which is all easy to use. Visit http://www.dovepress.com/testimonials.php to read real quotes from published authors. 